As the patient holds the chest in full expiration, the posterior application of the strap is completed with as much downward pressure as possible. Two straps applied in this manner are usually sufficient. A horizontal strap helps in anchoring the ends of the two main straps. The accompanying photograph further illustrates the manner of application.

Clinical experience with several cases of upper lobe pleurisy, in which this method of fixation of the chest was tried, has proved its effectiveness. The patient experienced almost immediate relief in each instance in which this method of treatment was employed.

\section{THERAPEUTIC APPLICATION}

The method is applicable in:

1. Upper lobe and apical pleurisy occurring in the course of tuberculosis, pneumonia and those due to other infections, when relief from distress is necessary.

2. Fracture of the four upper ribs or other injury of the upper thorax, when immobilization of the chest is desirable.

3. Apical tuberculosis, to augment Nature's attempt at fixation of the affected apex.

\section{HEMOPERITONEUM WITH BLUISH DISCOLORED UMBILICUS: REPORT OF CASE}

Melmuth H. Sternaerg, M.D., Jersey City, N. J.

History.-S. F., man, aged 61, a German saloonkeeper, was admitted to the hospital, Sept. 5, 1922, with the complaint of "enlarged abdomen." The family history was essentially unimportant. He denied all acute infectious diseases and venereal disease. He was the father of one grown son; his wife denied any miscarriages. Twenty-five years before, he suffered with nonbleeding hemorrhoids, which spontaneously disappeared. Seven years before, he was troubled with varicosities and edema of the lower extremities. He admitted that he indulged heavily in beer, wine, tobacco and coffee. He also enjoyed a voracious appetite, which he satisfied freely.

Prior to threc months before his entrance into the hospital, he had no complaints. He noticed that his appetite became poor and he was constipated. He complained of pyrosis, belching of gas, fulness after eating, borborygmus and loss of weight and strength. Six weeks before, his abdomen became distended. For this, he was twice successfully treated with drugs. A third reappearance failed to subside under free catharsis. The abdomen became so enlarged that respiration was interfered with. September 2, the patient noticed a small amount of "black blood" in the stool. At no time was there any hematemesis or jaundice. September 3, abdom:nal puncture by Dr. Kopetchny yielded a dark, sanguineous fluid under pressure. The patient entered the hospital two days later.

Physical Eramination.-The man was heavy set, weiging 210 pounds $(95.4 \mathrm{~kg}$.), and of muddy complexion, with the typical hepatic facies. The temperature was $98 \mathrm{~F}$.; pulse, 100 ; respiration, 24 ; blood pressure, 120 systolic, 90 diastolic. There were no signs of hemorrhage or shock. The abdomen was symmetrically enlarged. There was shifting dulness in the flanks. A fluid wave was demonstrable. The umbilicus was prominent. Below it and surrounding it; in a half-moon, there was evident a bluish black area, on a level with the rest of the skin, and containing yellow and green spots. Superficial veins of the abdomen were sparse. The liver and spleen were not palpable. Hemorrhoids were present. Both extremities showed varicosities and pigmented skin.

Laboratory Findings.-Examination of the urine revealed: specific gravity, 1.026; very slight trace of albumin; occasional granular casts; negative as to bile and sugar.

Blood tests revealed: red blood cells, 2,880,000; poikilocytosis and anisocytosis; hemoglobin, 58 (Tallqvist); blood clotting time, two minutes; white blood cells, 9,400; polymorphonuclears, 74 per cent.; leukocytes, 26 per cent.

The fluid aspirated from the abdomen was bloody, with a specific gravity of 1.02 . One third of the volume was composed of cells. Cultures and smears were negative. The bile was negative, and special cells were negative. A smear showed blood cells, all types (normal).

September 8 , the abdomen was again punctured by Dr. Hamill, and 7,000 c.c. of serosanguinous fluid was removed. September 9, the patient died.

Necropsy Findings.-The patient had entered the hospital with a diagnosis of atrophic cirrhosis. Because of the hematoperitoneum, malignancy of the abdomen was suspected. A partial necropsy revealed a small cirrhotic liver, with a right lobe joined to the right leaf of the diaphragm by a large, soft, fungating cauliflower mass, which was ulcerated in parts and oozed blood from its center. Microscopically, this was shown to be an adenocarcinoma of the liver. No other focus was demonstrable.

CONTENT

In 1919, Dr. Thomas S. Cullen observed and described the presence of a bluish black discolored umbilicus in a few cases of tubal pregnancy, in which the abdomen contained an abundant quantity of free blood. Dr. Emil Novak ${ }^{1}$ has recorded two cases of tubal abortion with this sign. The discoloration is ascribed by Dr. Cullen to the imbibition of blood by the umbilicus from the peritoneum. This subject has received further consideration by Dr. Cullen." $\mathrm{He}$ believes that this sign may be of great value in cases in which the bleeding has been slow but persistent, and the clinical symptoms are not very evident. The interest in this case lies in the presence of a bluish discolored umbilicus in a man with hemoperitoneum due to adenocarcinoma of the liver.

St. Francis Hospital.

\section{A CASE OF KNOTTED AND IMPACTED URETHRAL CATHETER}

\section{J. Fox, M.D., and J. C. Sargent, M.D., Milwauket}

D. S., a white man, aged 22 , entered Milwaukee County Hospital complaining of an impaction of a self-inserted, sofí rubber urethral catheter. The family history was unimportant. The patient denied any venereal disease or unusual sexual practices. He stated that on one occasion, one year before, for no apparent reason, he found himself unable to void, and was relieved by catheterization by a physician. There had been no subsequent trouble until the present illness. Aug. 23, 1922, without apparent cause, he was again unable to void, and after a continence of twelve hours, the discomfort of a distended bladder impelled him to insert a rubber tubing and empty the bladder. He could not withdraw the rubber tube. It seemed solidly fixed, and the slightest traction resulted in agonizing pain in the region of the bladder neck. Becoming alarmed, he consulted a physician, who made several attempts to withdraw the tube, but, because of the excruciating pain, was unsuccessful. Following this, some blood appeared at the meatus, and in several hours, swelling and edema of the penis occurred. A dribbling of urine around the catheter soon developed and continued. On the second day after this accident, the patient presented himself at the Milwaukee County Hospital. He complained only of the impacted catheter. Urine was dribbling constantly around the tube. He seemed comfortable.

The general physical examination was entirely negative. A soft rubber tube, about the size and consistency of a No. 20 soft rubber catheter, protruded 3 inches from the meatus. Urine dribloled slowly around the tube. The penis was moderately swollen and edematous. The scrotum and contents were normal. The prostate was swollen and excruciatingly tender. The rubber tube was solidly fixed within the urethra, and the slightest traction resulted in severe pain. The systolic blood pressure was 120; diastolic, 75; temperature, 100 ; pulse, 84 ; respiration, 20.

The patient was anesthetized with chloroform for a moment, during which the rubber tube was withdrawn. It was so tightly fixed that, before it gave way, it seemed that the

1. Novak, Emil: Bluish Discoloration of the Umbilicus in Diagnosis of Ruptured Extra-Uterine Pregnancy, J. A. M. A. 78:643 (March 4) 1922 .

2. Cullen, T. S.: Surg., Gynec. \& Obst. 35:257 (Sept.) 1922 